Market Structure and the Timing of Technology Adoption with Network

Externalities

by
Jay Pil Choi, Columbia University

March 1996

Discussion Paper Series No. 9596-07

$$
\begin{aligned}
& d p 9596-07 \\
& \text { pages: } 26
\end{aligned}
$$




\title{
Market Structure and the Timing of Technology Adoption
}

\author{
with Network Externalities
}

by

\author{
Jay Pil Choi \\ Columbia University \\ Marcel Thum \\ Princeton University
}

March 1996

\begin{abstract}
The paper shows that in the presence of network externalities, consumers adopt conventional technologies too early; the waiting option for a newly emerging technology is not exercised enough. This problem is aggravated when the new technology is provided by a single producer with market power because any positive value created via waiting by current consumers will be ex post appropriated by the monopolist. Therefore, the monopolist's power to extract surplus operates against his own interests in this dynamic setting. The paper also shows how the producer of a new technology can partially overcome the problem of too little waiting by using licensing as a commitment device.
\end{abstract}

JEL Classification: L11, $\mathrm{O} 33$

Keywords: network externalities, standardization, licensing

Correspondence address:

Jay Pil Choi

Department of Economics

Columbia University

New York, NY 10027

U.S.A.

e-mail: jpc8@columbia.edu
Marcel Thum

Woodrow Wilson School

Princeton University

Princeton, NJ 08544

U.S.A.

e-mail: mthum@wws.princeton.edu 


\section{Introduction}

Most high-tech industries today are characterized by rapid technological progress and network externalities. When the choice of technology is largely irreversible and technology is improving over time, one important element of technology adoption is timing; an earlier adoption ensures a longer stream of benefits while one may be stuck with an inferior technology in the future. The decision on adoption timing is further complicated in the presence of network externalities if the superior technology under development is incompatible with the technology available today. In this case, consumers today have to incorporate the future consumers' decisions into their decision-making while the future consumers' decisions themselves are also influenced by the current consumers' decisions. ${ }^{1}$ In this paper, we explore how this intergenerational interdependency induced by network externalities influences the pattern of technology adoption under various market structures.

In order to analyze the relationship between market structure and the timing of technology adoption in the presence of network externaltities, we consider the following situation which is typical in these industries. There is a technology available today while a superior technology is on the horizon and will be available in the future. Potential users of technologies are assumed to arrive sequentially. The problem facing a consumer today is whether to buy a technology available today and enjoy a longer stream of benefits (from the ex post inferior technology) or to wait until tomorrow when a superior technology appears. In addition, an early adoption may entail the loss of network benefits if future consumers decide to buy a new technology which is incompatible with the current one. We derive the equilibrium technology adoption patterns under alternative market structures of perfect competition and monopoly in the provision of the new technology. When we compare these market outcomes with the socially optimal one, we find that there is a tendency for too little waiting by the first generation consumers in both cases,

\footnotetext{
${ }^{1}$ Choi (1994a) couches these interdependency in terms of the forward and backward externalities.
} 
consistent with the results of Choi (1994a). The intuition behind this result for the case of perfect competition is that when the first generation consumers adopt a technology early, they inflict negative externalities on the future consumers; either the future consumers are forced to buy an inferior technology to ensure compatibility or to lose compatibility in order to buy a superior technology. Under monopoly, the inefficiency due to an early adoption is exacerbated. The reason is that any positive value created via waiting by the current consumers will be ex post appropriated by the monopolist. Therefore, the monopolist's power to extract surplus operates against his own interests in this dynamic setting. This leads us to consider licensing as a commitment mechanism by the monopolist not to expropriate surplus created by the first period consumers as in Farrell and Gallini (1988) and Shepard (1987). It shall be shown that licensing enables the monopolistic supplier of the new technology to capture the market in a wider range of parameters.

This paper extends the work by Katz and Shapiro (1986) who analyze how the pattern of technology adoption changes according to the configuration of sponsorship of competing technologies. However, they do not consider the option of waiting by consumers, which allows them to ignore interim payoffs to consumers without affecting their main results. In a more recent paper, Katz and Shapiro (1992) also investigate the timing and compatibility decisions of the monopolistic supplier of a new technology. In their framework, however, the option of waiting is never exercised in equilibrium even though it is allowed. Finally, Choi (1994a) analyzes a similar problem of sequential and irreversible technology in the presence of network externalities with technology stochastically evolving over time. He consideres, however, only the case where technology is supplied competitively. Consequently, the effect of market structure on the timing of technology adoption is not the main concerns in Choi (1994a). ${ }^{2}$

The rest of the paper is organized in the following way. In section II, we present a basic model where we derive equilibrium outcomes under alternative market structures and compare them with the socially optimal one. In section III, we analyze licensing by the monopolist as a

${ }^{2}$ Choi (1994a) also considered the case of monopolistic supplier of emerging technology in the technology adoption process. His focus, however, was on the choice of $R \& D$ riskiness by the monopolist. 
way to commit to a future price and its welfare implications. Section IV considers various extensions of the basic model. Concluding remarks follow.

\section{The Model}

The basic setup is a variant of the seminal Katz and Shapiro (1986) framework. We consider a simple two-period model with two incompatible technologies $A$ and $B$. There are also two groups of consumers with the same size, 1 and 2 , who arrive sequentially at time $t=1$ and 2 , respectively. In the first period, only technology $A$ is assumed to be available. Technology $B$ becomes available in the second period. Hence, we will refer to $A$ as the conventional technology and to $B$ as the emerging technology. In this set-up, the choice facing the consumer group 1 that arrives at the market in period 1 is either to buy the only currently available technology $A$ or to wait until period 2 when the new technology $B$ emerges in the market. In period 2, a new group of consumers, 2, arrives on the market and makes a technology adoption choice between the two technologies $A$ and $B$, given the choice of group 1. As in Katz and Shapiro (1986), in cases of multiple equilibria, we simplify the analysis by assuming that consumers buying in the same period can coordinate their purchase decisions to choose the outcome that is Pareto preferred. This coordination assumption lets us treat each consumer group as a single representative consumer. We depart in an important way from the framework of Katz and Shapiro, however, by allowing the first period consumers the option of waiting. Since our focus is on the relationship between the market structure and the timing of technology adoption in the presence of the waiting option, we assume that the technology is irreversible and consumers are not allowed to make repeat purchases. ${ }^{3}$ This is a reasonable assumption for many markets under consideration, in particular when the goods are durable and the switching costs are relatively high.

What determines the consumers' decisions? Each consumer takes into consideration the two types of benefits that can be derived from using one of the technologies: the stand-alone

\footnotetext{
${ }^{3}$ For an analysis of planned obsolescence when repeat pruchases are possible, see Waldman (1993) and Choi (1994b).
} 
benefit and the network benefit. The stand-alone benefit reflects the value of a technology when it is adopted by only one group, which for technology $A$ and $B$ in each period are denoted by $a$ and $b$, respectively. Since we want to discuss the effects of a new emerging technology that is superior to the conventional one, we will assume that $b>a$. The difference between the two standalone values $\Delta=b-a$ describes the value of the technological progress. The second potential benefit a consumer may derive from using a technology is the network benefit. This is the benefit that consumers derive from sharing the same or compatible technology with the other group of consumers. In our case, compatibility is reached when both groups of consumers use the same technology $A$ or $B$. We will denote by $n$ the value each group of consumers attaches to the network benefit. This benefit is the same across groups of consumers since we assume that the size of each group is the same. ${ }^{4}$ There is no discounting. Finally, the marginal costs of producing a unit of each technology are assumed to be zero. The last two assumptions are made purely for the ease of exposition. Taking the discount factor and positive production costs explicitly into consideration would only add to the complexity of the notation without providing any further insight into the economic problem.

\section{The Social Optimum}

Before analyzing the outcomes under different market structures, we start out with the socially optimal configuration of technology adoption. A social planner can choose among the three possible patterns of technology adoption: both consumer groups adopt technology $A(A A)$, consumer group 1 opts for technology $A$ and consumer group 2 gets $B(A B)$, or group 1 waits until the second period and both consumer groups adopt $B$, the best technology available at that time, $(O B) .^{5}$ Welfare under each technology adoption is defined as the sum of individual benefits. Hence, we obtain:

\footnotetext{
${ }^{4}$ If the sizes differ across groups, the larger consumer group will attach less value to the network benefit. See Katz and Shapiro (1986) for an analysis of "size effect" in the evolution of technology adoption.

${ }^{5}$ We ignore the fourth possible alternative, $O A$, which is strictly dominated by the option of $O B$.
} 


$$
\begin{aligned}
& W_{A A}=a+2 \cdot(a+n)=3 \cdot a+2 \cdot n \\
& W_{A B}=a+(a+b)=2 \cdot a+b \\
& W_{O B}=0+2 \cdot(b+n)=2 \cdot b+2 \cdot n
\end{aligned}
$$

If both consumers use technology $A$, welfare $W_{A A}$ consists of the stand-alone benefit $a$ for the first consumer during period 1 and the stand-alone plus the network benefit for both consumers in period 2, as they use a common compatible technology. Similar interpretations can be applied to the other cases. Figure 1 depicts the socially optimal configuration of technology adoption. The horizontal axis measures technological progress $\Delta$ from technology $A$ to $B$. The vertical axis denotes the value of the network effect $n$. Since technological progress and network effect are assumed to be positive ( $\Delta>0$ and $n>0$ ), we can confine our analysis to the positive quadrant.

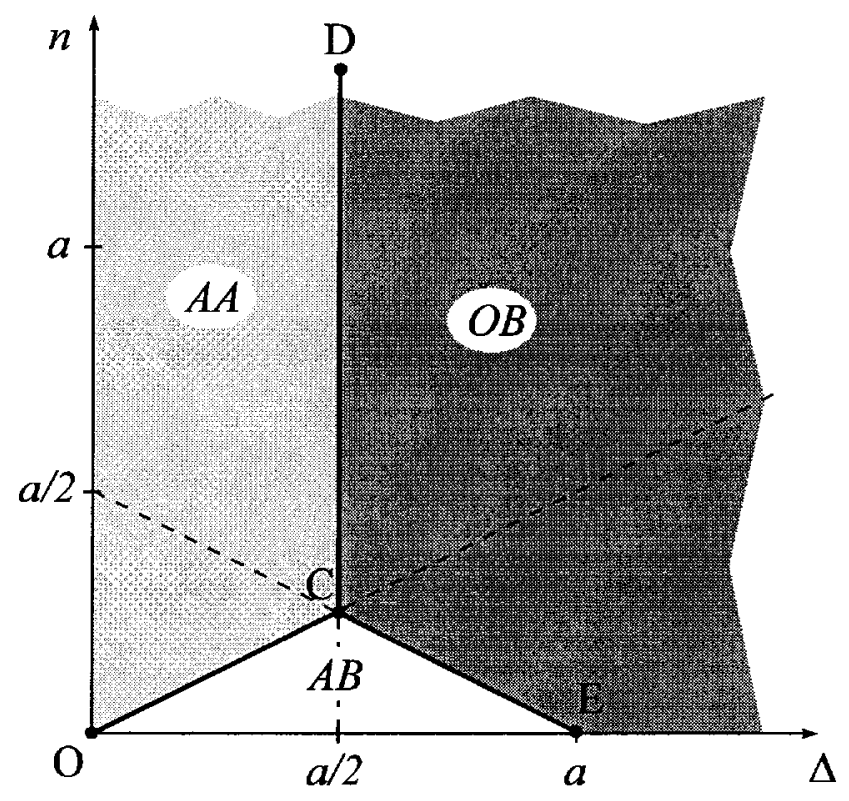

Figure 1: The Social Optimum

If technological progress is small relative to the stand-alone benefit of the conventional technology $(\Delta<a / 2)$ and to the network effect $(\Delta<2 n)$, standardization on the $A$ technology is optimal (left of OCD). The first consumer can immediately benefit from the stand-alone value of the product; it is not worth foregoing the current stand-alone benefit $a$ by waiting for a slightly higher technological value in the second period if $\Delta<a / 2$. The socially optimal action for the 
second-period consumers is to follow suit in period 2 as the advantage from technological progress cannot outweigh the common network benefit for both consumers $(2 n)$.

In contrast, if the stand-alone value of the existing technology, $a$, is relatively high ( $a>2$ $n+\Delta)$, but the network effect is relatively unimportant $(n<\Delta / 2)$, standardization is not required in the optimum (below OCE). The first-period consumers should immediately adopt technology $A$ because waiting for the slightly better technology in the future is too costly, while the secondperiod consumers ought to choose an incompatible but superior one, $B$, because the loss in network benefits product is outweighed by the benefit of choosing a better technology.

Finally, the third case is the most interesting one (to the right of DCE). The first-period consumers should delay their adoption decision until the new technology emerges in the market. Both the advantage from technological progress and the network benefits for both consumer groups are sufficiently large to warrant the waiting and foregoing the immediate benefit from the stand-alone use of $A$. In the following sections, we will analyze to what extent different market environments and competitive settings will influence the waiting decision in the adoption process.

\section{The Competitive Case}

In our first setting, both technologies are competitively supplied. With many suppliers for each technology, there is no room for strategic price setting and prices are tied to marginal costs. Under the assumption of no production costs, this implies that $p_{A}=0$ in both periods and $p_{B}=0$ in the second period. We solve the game backwards starting with the second period subgame when the first-period consumers have already bought technology $A$ in period 1 , which we denote by $A_{1}$. In this situation, the second-period consumers face the decision either to follow the previous consumers on technology $A$ (denoted by $A_{2}$ ) or to adopt the new but incompatible technology $B$ with its technically superior features (denoted by $B_{2}$ ). The second-period 
consumers prefer $A$ over $B$ if and only if the network benefits of choosing the same technology $A$ exceed the degree of technical advantage held by technology B:

$$
A_{2}\left\{\begin{array}{l}
> \\
<
\end{array}\right\} B_{2} \Leftrightarrow n\left\{\begin{array}{l}
> \\
<
\end{array}\right\} \Delta
$$

given $A_{1}$

If the first-period consumers decide to delay their adoption decision until the second period, the analysis of this subgame is straightforward; both groups of consumers adopt the new superior technology $B$.

Figure 2 illustrates the competitive outcome in the familiar way. Above line OGJ $(n>\Delta)$, the second-period consumers will follow suit; the second-period consumers' best response is to adopt the same technology $\mathrm{A}$ as the first-period consumers. Below line OGJ $(n<\Delta)$, however, they will opt to choose the superior technology $B$, forgoing the benefit of compatibility.

To analyze the first period adoption decision, we have to distinguish between the alternative second period outcomes outlined above. Firstly, suppose that the second-period consumers will follow the first-period counterparts in their technology choice (above OGJ). In this case, if the first-period consumers choose technology A immediately (denoted by $A_{1}$ ), they receive the stand-alone benefit of $a$ in both periods and the network benefit in the second period $(2 \cdot a+n)$. If the first-period consumers wait until the next period to adopt the new technology $B$ (denoted by $B_{1}$ ), they get $b+n$. Therefore, the first-period consumers' decision can be characterized by

$$
A_{1}\left\{\begin{array}{l}
> \\
<
\end{array}\right\} B_{1} \quad \Leftrightarrow \quad 2 \cdot a+n\left\{\begin{array}{l}
> \\
<
\end{array}\right\} b+n
$$

if $A_{2}$ is the second-period consumers' best response to the adoption of technology $A$ in the first period. Hence, a competitive market will lead to standardization on the $A$ technology, if both conditions, $2 \cdot a>b$ (for the first-period consumers) and $n>\Delta$ (for the second-period consumers), are fulfilled. In figure 2, these cases are illustrated by the area left of OGH.

Secondly, suppose that the adoption of technology $B$ is the optimal strategy for the second-period consumers (below OGJ). In this case, we can derive similar conditions: 


$$
A_{1}\left\{\begin{array}{l}
> \\
<
\end{array}\right\} B_{1} \Leftrightarrow 2 \cdot a\left\{\begin{array}{l}
> \\
<
\end{array}\right\} b+n .
$$

The first consumer will immediately adopt technology $A$ if the stand-alone benefit during the first period ( $a$ ) exceeds the benefit from waiting which consists of the network effect $(n)$ and the value of technological progress $(\Delta)$. Hence, non-standardization is the competitive outcome in the area below line OFE, i.e. when both inequalities $a>n+\Delta$ (below FE) and $n<\Delta$ (below OF) hold. In all other cases (left of EFGH), it is optimal for the first consumer to wait for the emerging superior technology and standardization on $B$ is achieved in the second period.

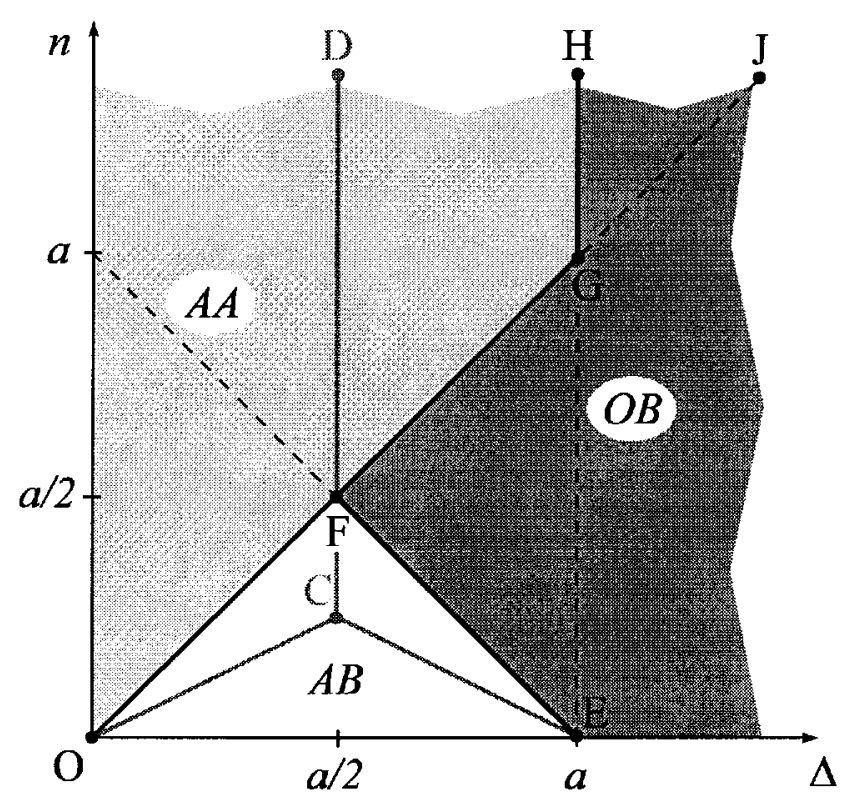

Figure 2: The Competitive Case

Now we are able to discuss the welfare implications. Comparing the competitive outcomes to the social optimum, three types of inefficiencies can be identified. First, for the parameter values belonging to area $\mathrm{OCF}$, competitive market outcome leads to non-standardization (AB) whereas the social optimum calls for standardization on $A$ (AA). The advantage from the superior technology $B$ exceeds the network benefit for the second-period consumers, which impels them to adopt technology $B$. In doing so, however, the second-period consumers neglect the network externality that could have accrued to the first-period consumers if they joined the first consumers on technology $A$. This is the well known inefficiency, called excess momentum, in the network 
externality literature. Second, in the area of CFE, the market leads to non-standardization (AB) instead of an optimal standardization on technology $B(\mathrm{OB})$. In this case, the first-period consumers adopt the existing technology in order to obtain the stand-alone benefit over both periods rather than wait for the new technology to be available. They thereby neglect the possible network externality on the second-period consumers. The reason is that by committing to the existing technology too early, they deprive the latter group of the chance to coordinate on the new technology. This results in too little waiting for the emerging technology on the part of the firstperiod consumers. Third, in the area of DFGH, standardization is achieved on technology $A$ (AA) but the optimal configuration is waiting and standardizing on $B(\mathrm{OB})$. This outcome is an even stronger case of too little waiting. The first-period consumers not only adopt the inferior technology $A$ too early but by doing so also force the second-period consumers to forgo the benefits of the technological progress in order to maintain compatibility with them.

In the next section, we will analyze whether this result of too little waiting in the adoption process carries over when the new technology is provided as a sponsored technology.

\section{Sponsored Emerging Technology}

Due to intellectual property rights such as patent, the developer of a new technology often retains an exclusive right to sell the technology. Then, the producer can act as a monopolist, setting prices strategically with regard to the competing product and appropriating some profits on his proprietary technology. This is the case to be discussed in this section. The conventional technology $A$ is still assumed to be competitively provided.

We first note that the second period patterns of technology adoption in the market equilibrium are independent of the sponsorship configurations. The reason is that which technology captures the market in the second period depends on the lowest price the sponsor of the new technology is willing to charge. This lowest price is given by the production cost, and is the same as the price of the technology when it is competitively supplied. In other words, the line 
OGJ (figure 3) once again separates the two relevant regions for the second period subgame. Above this line, the second-period consumers will adopt the same technology as the first-period consumers; below this line, the adoption of technology $B$ is a dominant strategy.

To verify our claim, suppose that the first-period consumers have adopted technology $A$ in the first period. Then, the second-period consumers make their adoption decision according to

$$
A_{2}\left\{\begin{array}{l}
> \\
<
\end{array}\right\} B_{2} \Leftrightarrow a+n\left\{\begin{array}{l}
> \\
<
\end{array}\right\} b-p_{B} \quad \text { given } A_{1}
$$

where $p_{B}$ is the price for the sponsored technology. To maximize profits the producer of technology $B$ sets the highest possible (non-negative) price that still attracts the second-period consumers. The price of the sponsored technology, therefore, amounts to $p_{B}=\max \{\Delta-n, 0\}$. If the price becomes negative, the producer of $B$ drops out of the competition and the second-period consumers will adopt technology $A$. This will occur when $n>\Delta$. In all other cases, the producer of $B$ can profitably set prices to make his product the second-period consumers' best choice. If the first-period consumers have chosen the waiting option, the producer of technology $B$ can always set the price marginally below $p_{B}=\Delta$ which attracts both consumers to his technology and leads to positive profits.

The consideration of a sponsored technology, however, has important consequences when we consider group 1's decision in the first period. The first-period consumers recognize the monopolistic supplier's incentive to extract rents through its ability to set the prices in the future, and take this opportunistic behavior of the sponsor of technology $B$ into account when they make their adoption decision. Suppose again that the second-period consumers will follow suit in their adoption decision (above OGJ). In this case, the choice between adopting technology $\mathrm{A}$ in the first period $\left(A_{1}\right)$ and the option of waiting and adopting technology $B\left(B_{1}\right)$ is made according to

$$
A_{1}\left\{\begin{array}{l}
> \\
<
\end{array}\right\} B_{1} \Leftrightarrow 2 \cdot a+n\left\{\begin{array}{l}
> \\
<
\end{array}\right\} b+n-p_{B}
$$

where the second-period price of technology $B, p_{B}$, will be set at the profit maximizing level of $p_{B}=\Delta$ by the monopolistic supplier. Inserting the equilibrium price, the condition for 
technology A being chosen is given by the inequality $a>0$. Hence, it is always optimal for consumer group 1 to choose the old technology $A$; the option to wait for the new technology is never exercised. The intuition for this result is as follows. Note that waiting on the part of the first-period consumers enhances the value of technology $B$ in the second period because it enables the emerging technology $\mathrm{B}$ to compete on a level playing field with the conventional technology due to the lack of an installed base for technology $A$. However, with the emerging technology sponsored, the price of technology $B$ is no more tied to its marginal cost. As a result, any surplus generated by the waiting of the first-period consumers is extracted by the monopolistic supplier of technology B. Unless the sponsor of $B$ has a credible commitment mechanism to a future price that will limit his future ability to extract the consumer surplus, it is impossible to induce the first-period consumers to delay their adoption decision. We can conclude that the market solution with $B$ as the sponsored technology leads to standardization on the conventional technology $A$ in the complete region above line OGJ.

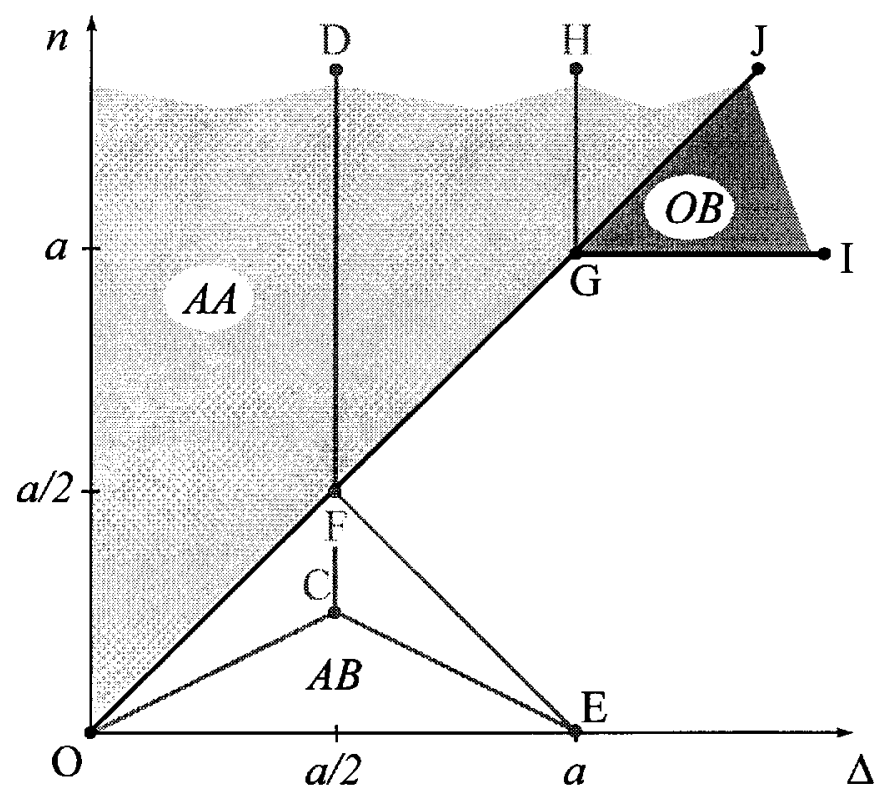

Figure 3: Sponsored Technology

Suppose now that the second-period consumers will choose technology $B$ regardless of the first-period consumers' decision (below OGJ). This changes the first-period consumers' decision to 


$$
A_{1}\left\{\begin{array}{l}
> \\
<
\end{array}\right\} B_{1} \quad \Leftrightarrow \quad 2 \cdot a\left\{\begin{array}{l}
> \\
<
\end{array}\right\} b+n-p_{B}
$$

where the equilibrium price remains at $p_{B}=\Delta$ when the first-period consumers decide to wait for the emerging technology. The first-period consumers will commit themselves to technology $A$ $\left(A_{1}\right)$ if the stand-alone benefit in the first period exceeds the network value in the second period $(a>n)$. In figure 3 , this condition leads to the adoption pattern $A B$ below line OGI. If $a<n$, the first-period consumers can retain a higher surplus by adopting technology $B$ despite the rentextracting price of the sponsored product, and so the first-period consumers wait for the emerging technology which leads to the standardization on $B$ in the second period (in the area IGJ).

Taking a closer look at the welfare effects, we observe that the region of inefficiency is strictly greater than in the competitive case. Inefficient non-standardization is extended by the area EFGI where we had efficient standardization on $B$ in the competitive market. The region of inefficient standardization on the old technology has also increased for the parameter values in area HGJ. In both cases, the source of the increased inefficiency is the fact that the first-period consumers do not exercise the option of waiting often enough. In an effort to guard themselves against the ex post opportunistic behavior of the future monopolist of the emerging technology, they forego the option of waiting and adopt immediately the conventional technology. In some cases (HGJ), this early adoption on the part of the first-period consumers induces even the second-period consumers to switch from the emerging technology to the adoption of the old technology. This general tendency of too little waiting for the emerging technology on the part of the first-period consumers when it is sponsored vis-à-vis when it is competitively supplied, and the resulting bias against the sponsored technology, is in sharp contrast to Katz and Shapiro's (1986) result where there is a bias toward the sponsored technology. This contrast illustrates the importance of considering the option of waiting explicitly in the technology adoption processes. The discretionary power to set the price in the second period undermines the sponsor's strategic position in the battle to establish a new standard unless he can devise a mechanism to self-limit his ability to extract the consumer surplus. 


\section{Licensing as a Commitment Device}

As seen in the previous section, the bias against the waiting option and the sponsored technology is due to the monopolist's inability to make a binding promise to the future price of the new technology. In this section, we investigate whether licensing for the purpose of attracting competition can be used as a credible mechanism to commit the monopolist to a low future price. Consider a situation where the developer of the new technology $B$ offers a licensing contract in the first period to provide the technology at the royalty rate of $r^{6}$ Once the technology is transferred in the second period, the developer and the licensees compete in a Bertrand fashion. Competition among the licensees guarantees that the market price in the second period cannot exceed the royalty rate. This ceiling on the future price made possible by licensing can serve as a commitment mechanism not to expropriate the consumer surplus and may induce the first-period consumers, who otherwise would have bought the competitive technology $A$, to wait. In this section, we will also investigate in detail the social welfare consequences of licensing in the technology adoption.

Let $r$ be the royalty that is charged per unit of the new technology sold in the second period. By the same logic as in the previous section, the adoption decision of the second-period consumer is once again divided by line OGJ in figure 4.7 Above line OGJ, the second-period consumers will follow the adoption decision of the first-period consumers; below this line, second-period consumers adopt technology B regardless of the adoption decision of the firstperiod consumers. We can immediately discuss the decision problem for the first-period consumers in these two cases. If the second-period consumers follow the earlier technology adoption, the first-period consumers know that they will get the network effect in addition to the

\footnotetext{
${ }^{6}$ Licensing contracts are frequently negotiated before a new product is fully developed. A recent example can be found in the Digital Video Disc (DVD) technology where nine major companies have agreed on technical specifications and licensing conditions before the product is introduced in the market; see New York Times, December 9, 1995, p. 39. Farrell and Gallini (1988, pp. 676-677) discuss several ways for an early licensing of future technologies. A general description of licensing negotiations and the various elements of licensing contracts can be found in Root (1987).

${ }^{7}$ The licensing strategy is used in order to credibly announce prices lower than the one under a discretionary price policy. This strategy aims at the decision of the first-period consumers but leaves the outcome of the second period subgame unchanged (though prices might be lower).
} 
stand-alone benefit. If the first-period consumers wait and buy technology $B$, they will have to pay a price according to the royalty $r$ :

$$
A_{1}\left\{\begin{array}{l}
> \\
<
\end{array}\right\} B_{1} \Leftrightarrow 2 \cdot a+n\left\{\begin{array}{l}
> \\
<
\end{array}\right\} b+n-r
$$

Waiting for technology $B$ is the optimal choice if $r<\Delta-a$. What is the appropriate royalty for the developer? To maximize profits the developer of $B$ sets the royalty at a level that just fulfills the above inequality in order to induce the first-period consumers to wait and earns him nonnegative profits. Note that the profitability of the licensing strategy is constrained by a nonnegative royalty $(r \geq 0)$. This implies that standardization on technology $B$ will be achieved whenever $a<\Delta$, i.e. to the right of line GH (and above GJ).

In the second case, where the second-period consumers will adopt technology $B$ anyway, the first-period consumers forego the network benefit by choosing $A$. Therefore, they face the following decision problem:

$$
A_{1}\left\{\begin{array}{l}
> \\
<
\end{array}\right\} B_{1} \quad \Leftrightarrow \quad 2 \cdot a\left\{\begin{array}{l}
> \\
<
\end{array}\right\} b+n-r .
$$

The first-period consumer are willing to wait for the emerging technology $B$ if $r<\Delta+n-a$. On the developer's side, the profits from licensing the new product and selling to the both generations of consumers have to exceed the profits that could be achieved by selling the product only to the second-period consumers. From the previous section, we already know that the second period price is $p_{B}=\Delta-n$ in the case of early adoption (non-standardization). Therefore, the licensing strategy will only be chosen if $2 \cdot r>p_{B}=\Delta-n$. Combining the profit condition and the adoption decision, we find that the waiting and standardization on technology $B$ will be an equilibrium only if $2 \cdot a<\Delta+3 \cdot n$. The cases where the licensing strategy induces consumer 1 to wait and achieve standardization on technology $B$ are shown to be the area above line FK (and below FJ) in figure 4. 


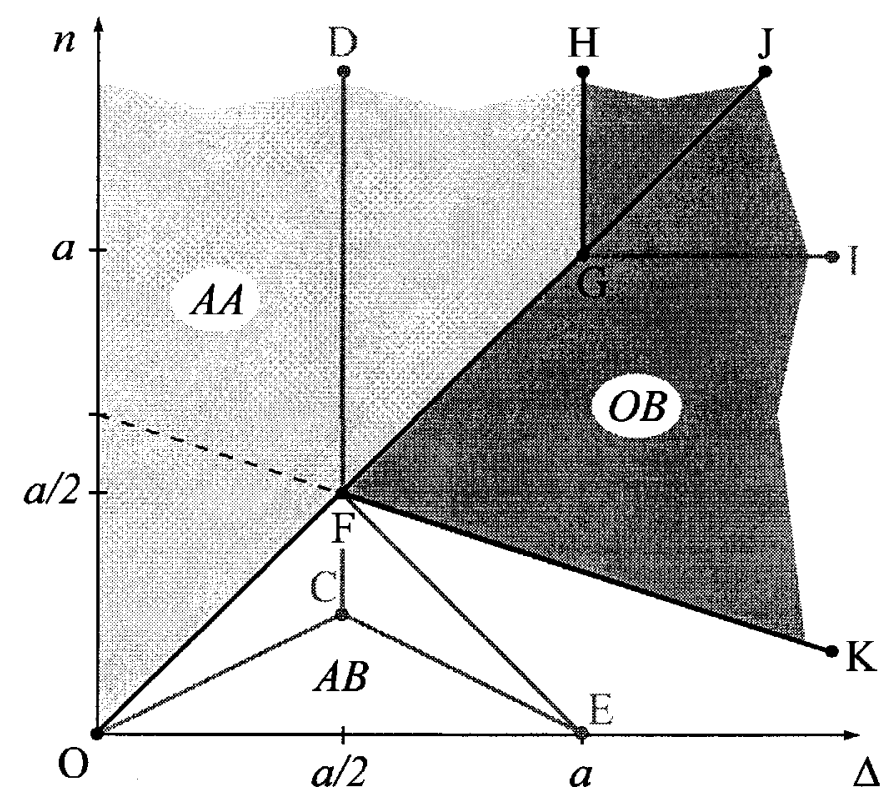

Figure 4: Licensing as a Commitment Device

Comparing the adoption pattern under licensing (figure 4) with the case of no licensing (figure 3), we can state that the licensing strategy indeed improved the market position for the new technology. The area for which adoption of the new standard technology $B$ is an equilibrium, has increased by the areas HGJ and IGFK. Moreover, this induced change due to licensing is also welfare-improving. In the cases where the developer of technology $B$ faced the threat of a complete failure (above OGJ), the licensing strategy brought us even back to the fully competitive case. The reason for this result is that the developer has only the alternatives of all or nothing in terms of market penetration in this case. He is, therefore, willing to lower the royalty rate until zero to capture the market in the first period. This implies that the market adoption configuration under licensing is the same as the case when the emerging technology is competitively supplied (at the marginal cost of zero) as verified by the comparison of figures 2 and 4. .

Now consider the case that the developer of the new technology is able to sell to the second-period consumers even in the face of installed base of technology $A$ (below OGJ). In this case, licensing restores efficiency by increasing the area of waiting by the first-period consumers to some extent (area IGFK), but does not replicate the case of competitive suppliers. The reason 
is that the sponsor does not face the all-or-nothing choices any more. Even if he concedes the market to technology $A$ in the first period, but he can still capture the second-period market. $\mathrm{He}$ is not, therefore, willing to reduce the royalty rate until zero to induce the first-period consumers to wait; the sponsor can have a higher profit from exploiting the high willingness to pay from the second-period consumers instead of charging a low uniform royalty for both generations of consumer groups. ${ }^{8}$ This implies that there is too little waiting compared to the competitive case (by area EFK) even under licensing when the emerging technology is sponsored.

\section{Strategic Competition between Two Sponsored Technologies}

So far we have analyzed the consumer's waiting behavior under the assumption that only the developer of the new technology can use prices and licensing as instruments in the strategic competition for standards. Here we will consider the case where the conventional technology is also provided by a single producer instead of being competitively supplied. The strategic competition between the two sponsored technologies further reinforces our point that the consumers' waiting behavior is crucial for the emergence of efficient standards and that, in general, there is too little waiting for emerging technologies.

\section{Two Sponsored Technologies without Licensing}

The conventional technology $A$ is now provided by a single supplier who is free to set prices in both periods. As product $B$ enters the market in the second period, the price of this product will be set at this later stage. In the first variant of the model, we ignore the possibility of licensing for both technologies.

In order to find the adoption pattern when both technologies are sponsored it will not be necessary to go through all the formal derivations again. A moment's reflection tells us that the

\footnotetext{
${ }^{8}$ Thum (1994) discusses how various types of contracts can be used for efficiency enhancing price-discrimination. The model, however, does not allow for waiting on the consumers' side.
} 
adoption pattern does not change whether only technology $B$ or both technologies are sponsored; the outcome with two sponsored technologies will be the same as in figure 3 .

To prove this point, recall that technology adoption pattern in the second-period subgames does not depend on the sponsorship configuration. In other words, line OGJ is once again the relevant dividing line for the purpose of predicting the outcomes of the second-period subgames. If the parameter values fall in the area above line OGJ, the sponsor of technology A faces an allor-nothing proposition. If the sponsor concedes the first-period market and lets the consumers wait, he gets zero profit. As an alternative strategy, however, he can at least imitate the previous outcome by setting the price for his product at zero in the first period. In this way, he can build an installed base for future competition and capture some profit in the second period. Since the latter strategy is better, the market outcome is AA above OGJ line as in the case where only technology B is sponsored.

The adoption pattern will not change in the area below OGJ line, either. In this case, technology B will capture the market regardless of what happened in the first period. This implies that the sponsor of technology A cannot engage in penetration pricing which sells technology A below marginal cost because he cannot recoup the loss in the future. Therefore, the lowest price he is willing to charge in the first period is his marginal cost. This implies that the first period technology adoption configuration is the same as the case when technology $A$ is competitively supplied. This completes our argument that whether technology A is sponsored or not does not affect the technology adoption pattern.

Two Sponsored Technologies with Licensing of the Emerging Technology

Now suppose that the new technology can be licensed while maintaining the assumption that both technologies are sponsored. If we consider the region under line OGJ, once again we can conclude that the sponsorship of technology A does not make any difference when compared to the case where technology A is competitively supplied (figure 4) due to the same reason stated 
above in the case of no licensing; there is no room for penetration pricing for the sponsor of technology A since the second-period market is captured by the emerging technology anyway. In the region above OGJ line, however, the sponsorship of the conventional technology can make a difference because the sponsor of technology A can respond by penetration pricing in the face of the licensing strategy by the sponsor of technology $\mathrm{B}$ due to all-or-nothing type of competition. More specifically, the first-period consumers face the following adoption decision problem:

$$
A_{1}\left\{\begin{array}{l}
> \\
<
\end{array}\right\} B_{1} \Leftrightarrow 2 \cdot a+n-p_{A 1}\left\{\begin{array}{l}
> \\
<
\end{array}\right\} b+n-r_{B},
$$

Firm $B$ can capture the second-period market only when the first-period consumers delay their technology adoption until the second period. Hence, firm $B$ is willing to lower its royalty even to zero if necessary $\left(2 r_{B}>0\right)$. For firm $B$ to be successful with this licensing strategy, it should not be profitable for firm $A$ to establish its product as standard, i.e., $p_{A 1}+p_{A 2}<0$; or, using the information on the second period price $\left(p_{A 2}=n-\Delta\right)$, we should have $p_{A 1}<\Delta-n$. This implies that the licensing strategy of firm $B$ can induce the first-period consumers to wait for the emerging technology if $a+n<2 \cdot \Delta$. In figure 5, this condition holds for all cases to the right of GL. Compared to the situation where product $A$ was a non-sponsored technology, the effectiveness of the licensing strategy is reduced (GL instead of GH). The reason can be found in the strategic price setting by the sponsor of the old technology that offsets the socially beneficial effects of the licensing by the sponsor of the new technology; prices for good $A$ are reduced below marginal costs in the first period in the hope that the initial losses can be recouped by the second-period profits. 


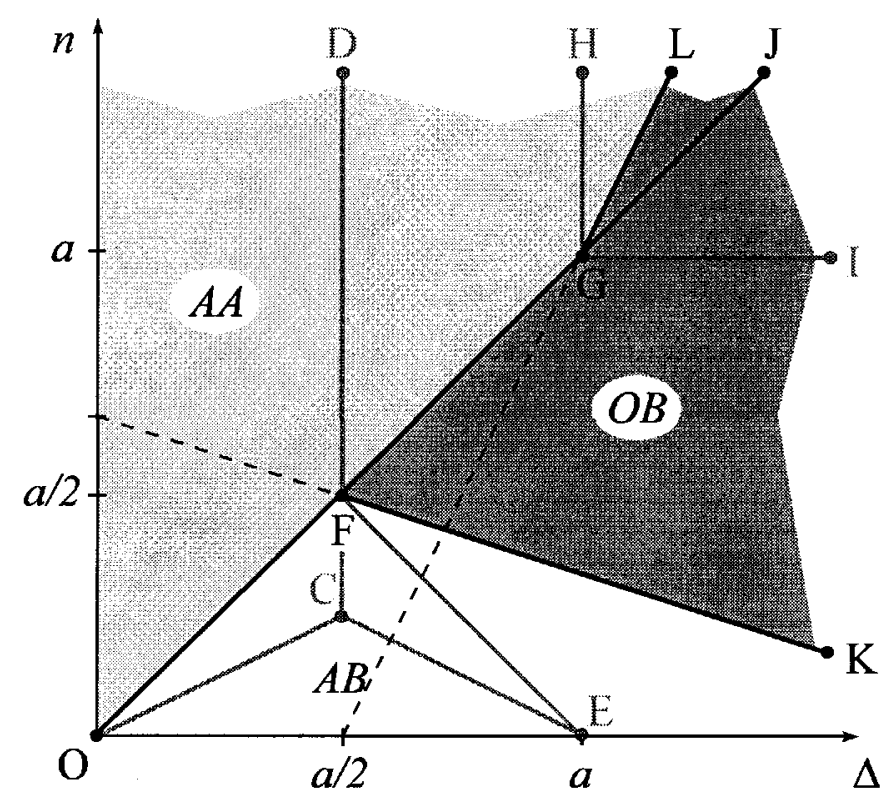

Figure 5: Two Sponsored Technologies with Licensing of Technology B

\section{Two Sponsored Technologies \& Licensing of Both Technologies}

In the previous section, firm $A$ had the opportunity of strategic price setting, but the licensing strategy was reserved for the emerging technology only. Now, firm $A$ has the same set of strategies as its disposal as the developer of technology $B$. This implies that firm $A$ can also commit to its second period price through licensing at a fixed per unit royalty.

To analyze how the availability of licensing strategy can be strategically employed by firm $A$, note that licensing is useful only in changing the adoption behavior of the first-stage. The technology adoption pattern in the subgames starting from the second-period depends only on the cost configuration. This implies that when the technology adoption pattern is either $\mathrm{AA}$ or $\mathrm{AB}$ even without licensing, licensing is redundant for firm A because it already captures the market in the first period (see the Appendix for a formal proof).

We confine the analysis, therefore, to the case where the first-period consumers wait for the emerging technology and standardization on $B$ is achieved without the licensing of technology A (right of LGFK in figure 5). To establish its own product as the standard via 
licensing, firm $A$ has to set the current price and the future royalty according to the conditions below.

$$
\begin{array}{ll}
A_{2}>B_{2} & \Leftrightarrow \quad a+n-r_{A}>b-r_{B} \\
A_{1}>B_{1} & \Leftrightarrow \quad 2 \cdot a+n-p_{A 1}^{L}>b+n-r_{B},
\end{array}
$$

where $r_{i}$ is the second period price of technology $i$ determined by the royalty rate and $p_{A 1}^{L}$ is the first period price for technology $A$. For standardization on $A$ to be an equilibrium, producer $B$ must be driven out of the market $\left(r_{B}<0\right)$. Hence, firm $A$ could charge a price of $p_{A 1}^{L}=a-\Delta$ and $r_{A}=n-\Delta$ in period 1 and period 2 , respectively. The licensing strategy, however, will only be undertaken, if the total profits from this strategy is nonnegative.

$$
\pi_{A A}>\pi_{O B}(=0) \Leftrightarrow p_{A 1}^{L}+r_{A}=a+n-2 \cdot \Delta>0
$$

which is fulfilled above line MGL in figure $6 .{ }^{9}$

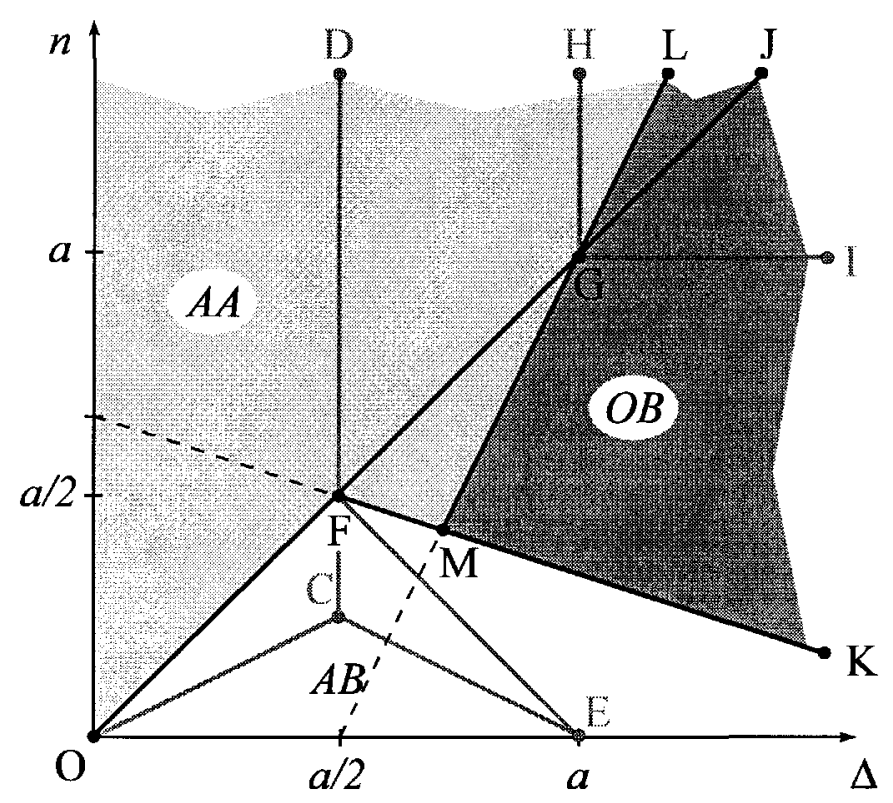

Figure 6: Two Sponsored Technologies with Licensing of Both Technologies

\footnotetext{
${ }^{9}$ In the area FGM, the second period royalty is negative. Committing to a subsidy of second period consumption is a profitable strategy as it attracts first period consumers to technology A. Overall profits are non-negative. Low royalties are common for many network technologies. Including the know-how transfer and other indirect benefits, effective licensing fees might well be negative. With negative royalties, the following problem may arise. Licensees have an incentive to produce a large quantity of the good just to collect the production subsidy in period 2. However, this problem can be avoided if the royalty is linked to sales (and not to output) or if marginal costs of production including the negative royalty are strictly positive. We do not explicitly incorporate this aspect into our model.
} 
The availability of the licensing strategy to the conventional technology has increased the number of cases where an established product could succeed over the emerging technology. Even without licensing, the market was characterized by too little waiting for a new technology on the part of the first-period consumers. The licensing strategy of the established firm, therefore, aggravates the misallocation. We conclude that, in contrast to a licensing strategy used for a new technology that can help mitigate the waiting problem, a licensing strategy used by an established technology exacerbates the inefficiencies caused by the early technology adoption.

\section{Conclusion}

The paper started from the presumption that consumers have not only the choice among a set of currently available technologies but have also the opportunity to wait for newly emerging technologies. We found that consumers are too impatient with respect to this waiting option and adopt too early a currently available technology. This result can already be achieved in a completely competitive environment. When both technologies are offered at marginal cost prices, early consumers neglect the network benefit they could generate for the subsequent consumers and, from the social planner's viewpoint, adopt the conventional technology in too many cases.

This problem, however, is worsened when the new technology is sponsored. Anticipating that any consumer surplus generated by waiting will be appropriated by the monopolistic supplier of the new technology, the early consumers will exercise the option of waiting even less. To mitigate this problem, we considered licensing as a credible commitment mechanism not to expropriate future consumer surplus. By attracting competitors as second sourcing possibilities, licensing was shown to alleviate the lack of waiting problem. However, it was not able to

eliminate the problem completely. The producer has too few incentives to use the licensing strategy in order to induce consumers to wait for an emerging technology. Moreover, the use of the licensing strategy may even be detrimental to the social welfare if the producer of the established technology also has the opportunity to compete with this strategic instrument. 
Appendix: Proof that licensing by firm A cannot be profitable when the adoption pattern is $\mathrm{AB}$ without licensing (area below OFK in figure 5).

A licensing strategy of firm $A$ would be successful if the allocation could be profitably changed to standardization on technology $A$. This can be achieved if the following two conditions are satisfied:

$$
\begin{array}{lll}
A_{2}>B_{2} & \Leftrightarrow \quad a+n-r_{A}>b-r_{B} & \text { given } A_{1} \\
A_{1}>B_{1} & \Leftrightarrow & 2 \cdot a+n-p_{A 1}^{L}>b+n-r_{B},
\end{array}
$$

where $r_{i}$ is the second period price of technology $i$ determined by the royalty rate and $p_{A 1}^{L}$ is the first period price for technology $A$. For standardization on $A$ to be an equilibrium, producer $B$ must be driven out of the market $\left(r_{B}<0\right)$. Hence, firm $A$ could charge a price of $p_{A 1}^{L}=a-\Delta$ and $r_{A}=n-\Delta$ in period 1 and period 2 , respectively. The licensing strategy, however, will only be undertaken, if the total profit from this strategy exceeds the profit from non-standardization which is achieved without this licensing strategy:

$$
\pi_{A A}>\pi_{A B} \quad \Leftrightarrow \quad p_{A 1}^{L}+r_{A}=a+n-2 \cdot \Delta>p_{A 1}=a-n
$$

or $n>\Delta$, which can never be fulfilled in the relevant range. Hence, it does not pay for the producer of the $A$ technology to license his product for the second period competition. The increase in the first consumers willingness to pay (due to the network effect) is always offset by the necessary subsidization of the second consumer. (The royalty is negative in this case. The developer of the $A$ technology has to promise a subsidy for each unit sold in period 2.) 


\section{References}

Choi, Jay Pil (1994a): "Irreversible Choice of Uncertain Technologies with Network Externalities", Rand Journal of Economics 25, pp. 382-401.

Choi, Jay Pil (1994b): "Network Externality, Compatibility Choice, and Planned Obsolescence", Journal of Industrial Economics 42, pp. 167-182.

Farrell, Joseph and Nancy T. Gallini (1988): "Second-Sourcing as a Commitment: Monopoly Incentives to Attract Competition", Quarterly Journal of Economics 103, pp. 673-694.

Katz, Michael L. and Carl Shapiro (1986): "Technology Adoption in the Presence of Network Externalities", Journal of Political Economy 94, pp. 822-841.

Katz, Michael L. and Carl Shapiro (1992): "Product Introduction with Network Externalities", Journal of Industrial Economics 40, pp. 55-83.

Root, Franklin R. (1987): Entry Strategies for International Markets, Lexington, MA: Lexington Books.

Shepard, Andrea (1987): "Licensing to Enhance Demand for New Technologies", Rand Journal of Economics 18, pp. 360-368.

Thum, Marcel (1994): "Network Externalities, Technological Progress, and the Competition of Market Contracts", International Journal of Industrial Organization 12, pp. 269-289.

Waldman, Michael (1993): "A New Perspective on Planned Obsolescence", Quarterly Journal of Economics 108, pp. 273-284. 


\section{5-1996 Discussion Paper Series \\ Department of Economics \\ Columbia University \\ 1022 International Affairs Bldg. \\ 420 West 118 th Street \\ New York, N.Y., 10027}

The following papers are published in the 1995-96 Columbia University Discussion Paper series which runs from early November to October 31 (Academic Year). Domestic orders for discussion papers are available for purchase at $\$ 8.00$ (US) each and $\$ 140.00$ (US) for the series. Foreign orders cost $\$ 10.00$ (US) for individual paper and $\$ 185.00$ for the series. To order discussion papers, please send your check or money order payable to Department of Economics, Columbia University to the above address. Be sure to include the series number for the paper when you place an order.

9596-01 Protectionist Response to Import Competition in Declining Industries Reconsidered J.P. Choi

9596-02 New Estimates on Climate Demand: Evidence from Location Choice

M. Cragg

M. Kahn

9596-03 Enforcement by Hearing

C.W. Sanchirico

9596-04 PreferentialTrading Areas and Multilateralism: Strangers, Friends or Foes?

J. Bhagwati

A. Panagariya

9596-05 Simplification, Progression and a Level Playing Field

William Vickrey

9596-06 The Burden of Proof in Civil Litigation

C. Sanchirico

9596-07 Market Structure and the Timing of Technology Adoption

J.P. Choi

M. Thum

9596-08 The Emergence of the World Economy

R. Findlay

9596-09 The Global Age: From a Skeptical South to a Fearful North

J. Bhagwati

9596-10 A Conformity Test for Cointegration

P.J. Dhrymes

9596-11 Identification and Kullback Information in the GLSEM

P.J. Dhrymes 